\title{
Batch and semi-continuous microalgal TAG production in lab-scale and outdoor photobioreactors
}

\author{
Giulia Benvenuti ${ }^{1}$ (D) $\cdot$ Rouke Bosma $^{1} \cdot{\text { Fang } \mathrm{Ji}^{2} \cdot \text { Packo Lamers }^{1} \cdot \text { Maria } \text {. Barbosa }}^{1}$ • \\ René H. Wijffels ${ }^{1,3}$
}

Received: 22 October 2015 / Revised and accepted: 21 June 2016 /Published online: 7 July 2016

(C) The Author(s) 2016. This article is published with open access at Springerlink.com

\begin{abstract}
Microalgal triglycerides (TAGs) represent a sustainable feedstock for food, chemical and biofuel industries. The operational strategy (batch, semi-continuous, continuous cultivations) has an impact on the TAG productivity. In this study, semi-continuous (i.e. with fixed harvesting frequency) and batch cultivations were compared on TAG production both at lab-scale and in outdoor cultivations. At lab-scale, the semi-continuous TAG productivity was highest for a cycle time of 2 days $\left(\mathrm{SC} 1 ; 0.21 \mathrm{~g} \mathrm{~L}^{-1}\right.$ day $^{-1}$ ) and similar to the maximum obtained with the batch (optimal harvest time; $0.23 \mathrm{~g} \mathrm{~L}^{-1} \mathrm{day}^{-1}$ ). Although TAG content was lower for $\mathrm{SC} 1(22 \%)$ than for the batch (35\%), higher biomass productivities were obtained with SC1. Outdoors, semi-continuous cultivations were subjected to a lower degree of stress (i.e. higher amount of nitrogen present in the system relative to the given irradiance) compared to lab-scale. This yielded low and similar TAG contents (10-13\%) in the different semi-continuous runs that were outdone by the batch on both TAG content (15-25\%) and productivity (batch, 0.97$2.46 \mathrm{~g} \mathrm{~m}^{-2}$ day $^{-1}$; semi-continuous, $0.35-0.85 \mathrm{~g} \mathrm{~m}^{-2}$ day $^{-1}$ ). The lab-scale experiments showed that semi-continuous strategies, besides leading to similar TAG productivities compared
\end{abstract}

Giulia Benvenuti

giuliabenvenuti@alice.it

René H. Wijffels

http://www.AlgaePARC.com

1 Bioprocess Engineering, AlgaePARC, Wageningen University, P.O. Box 16, 6700 AA Wageningen, The Netherlands

2 Biomass Engineering Center, China Agricultural University, P.O. Box 50, Beijing 100083, China

3 Biosciences and Aquaculture, Nordland University, N-8049 Bodø, Norway to the batch, could make TAG production cost effective by valorising also non-TAG compounds. However, optimization of outdoor semi-continuous cultivations is still required. For instance, the nitrogen supply and the harvest frequency should be adjusted on the total irradiance. Additionally, future research should focus on recovery metabolism upon nitrogen resupply.

Keywords Microalgae $\cdot$ TAG production $\cdot$ Batch . Semi-continuous $\cdot$ Outdoor

\section{Introduction}

Under adverse growth conditions, microalgae can accumulate high amounts of fatty acids in the form of triglycerides (TAGs). Microalgal TAGs are increasingly discussed as sustainable feedstock for the commodity markets (i.e. food, chemical and biofuel) (Wijffels et al. 2010; Mata et al. 2010; Draaisma et al. 2013). Microalgae as TAG cell factories offer several advantages over agricultural crops, which are currently used to produce those commodities. Besides producing valuable co-products (Mulders et al. 2014), microalgae can be cultivated on non-arable land and they have a low freshwater and fertilizer footprint when grown on wastewaters, sea- or brackish water. Most importantly, higher TAG productivities can be obtained with microalgae compared to agricultural crops (Chisti 2007; Hu et al. 2008).

At lab-scale, under defined conditions (e.g. temperature, light), high TAG productivities have already been achieved with some microalgal species (Griffiths and Harrison 2009; Breuer et al. 2012; Ho et al. 2014a; Benvenuti et al. 2014). However, it should always be validated whether the productivities obtained at lab-scale can be translated to outdoor cultivations, in which cells are subjected to varying (e.g. light, 
temperature) conditions. For this reason, outdoor pilot-scale research is essential to identify technical and process bottlenecks that should be tackled before scaling up.

When producing microalgal TAGs, an important aspect to evaluate is the adopted operational strategy (i.e. batch, semicontinuous, continuous cultivations), because it strongly affects process productivity (Benvenuti et al. 2015). Presently, TAG production is widely carried out in a two-step batch process (Zemke et al. 2010; Feng et al. 2011; Münkel et al. 2013; San Pedro et al. 2014) in which biomass is firstly produced under nitrogen replete conditions, and subsequently subjected to nitrogen $(\mathrm{N})$ starvation to trigger TAG accumulation. A batch process, besides being easy to operate, ensures high TAG contents $(>30 \% \mathrm{w} / \mathrm{w})$. However, after reaching a maximum within the first days of cultivation, TAG productivity decreases, due to a declining photosynthetic activity during N-starvation (Breuer et al. 2012; Benvenuti et al. 2014). Additionally, at the start of the batch, a fraction of the facility area and time are invested in inoculum production rather than in actual TAG production. Finally, a batch process implies downtime for reactor cleaning and startup in between runs, thus decreasing productivity and increasing labour, water and chemical demands.

These disadvantages possibly can be overcome by semicontinuous (Rodolfi et al. 2009; Bondioli et al. 2012) and continuous (Klok et al. 2013; Lucas-Salas et al. 2013; Wen et al. 2014) cultivations. Despite these operational modes are more complex to operate, they offer several advantages (Klok et al. 2014). Firstly, maximum TAG productivities, obtained within the first hours/days of batch cultivations, can potentially be maintained for longer periods in optimized (semi)- continuous processes. Secondly, cultivation settings (e.g. cycle duration) can be adjusted to changing light conditions. Finally, biomass production and TAG accumulation occur simultaneously in the same reactor, and downtime is negligible for long-term runs. Therefore, semi-continuous or continuous processes could result in a stable and robust process with higher TAG productivity compared to the classical batch approach.

Recent advances for (semi)-continuous TAG production have been reported (Bona et al. 2014; Terigar and Theegala 2014; Wen et al. 2014; Ho et al. 2014b). However, to develop a robust alternative process, it is necessary to perform a solid comparison of (semi)-continuous and batch strategies under exactly the same cultivation conditions (e.g. reactor design, light regime). Additionally, it is very important to perform process comparison not only under defined lab-scale conditions but also outdoors under changing weather conditions, and assess whether the findings obtained at lab-scale can be translated to outdoor cultivations.
The aim of this study was to investigate semi-continuous processes both at lab-scale and in outdoor cultivations and compare them to batch processes on TAG productivity.

\section{Materials and methods}

\section{Growth medium}

In all pre- and cultivation steps both at lab-scale and outdoors, cells were grown on a medium constituted of disinfected and filtered natural seawater (Oosterschelde, the Netherlands; (Benvenuti et al. 2015)) enriched with a nutrient stock consisting of (in $\mathrm{mM}$ ): HEPES (for pre-cultivation in Erlenmeyer flasks), 20; $\mathrm{KH}_{2} \mathrm{PO} 4,1.7 ; \mathrm{Na}_{2}$ EDTA, 0.56; $\mathrm{FeSO}_{4} \cdot 7 \mathrm{H}_{2} \mathrm{O}, 0.11 ; \mathrm{MnCl}_{2} \cdot 2 \mathrm{H}_{2} \mathrm{O}, 0.01 ; \mathrm{ZnSO}_{4} \cdot 7 \mathrm{H}_{2} \mathrm{O}, 2.3 \times$ $10^{-3} ; \mathrm{Co}\left(\mathrm{NO}_{3}\right)_{2} \cdot 6 \mathrm{H}_{2} \mathrm{O}, 0.24 \times 10^{-3} ; \mathrm{CuSO}_{4} \cdot 5 \mathrm{H}_{2} \mathrm{O}, 0.1 \times 10^{-3}$; $\mathrm{Na}_{2} \mathrm{MoO}_{4} \cdot 2 \mathrm{H}_{2} \mathrm{O}, 1.1 \times 10^{-3} ; \mathrm{NaNO}_{3}, 25$ (for pre-cultivation in Erlenmeyer flasks). During cultivation in reactors, nitrogen was supplied as described in "Experimental approach" section.

\section{Experimental approach}

Batch and semi-continuous cultivations were tested both under defined lab-scale conditions and in outdoor reactors and compared on TAG productivity.

Medium containing nitrogen $(\mathrm{N})$ was added at the start of the batch cultivations. At N-depletion, the cultures were supplied with a $\mathrm{N}$-free stock to prevent limitation of nutrients other than nitrogen, and subsequently cultured for 10 days. In the adopted semi-continuous strategy (Fig. 1), cells were inoculated in N-replete conditions (day 0 in Fig. 1). At N-

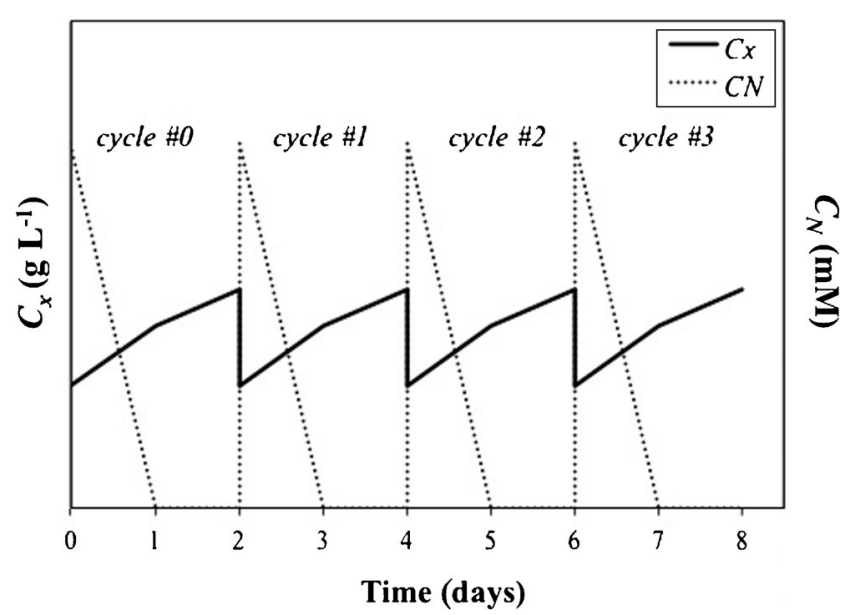

Fig. 1 Schematic representation of a semi-continuous cultivation 
depletion (day 1 in Fig. 1), TAG accumulation commenced. After a fixed number of days from $\mathrm{N}$-depletion (1, 2 or 3 days), the culture was partly harvested (day 2 in Fig. 1) and replenished with medium. In both lab-scale and outdoor cultivations, the harvested volume was chosen as such that the next cycle started at $1 \mathrm{~g} \mathrm{~L}^{-1}$. Nitrogen was dosed in the medium as such that each cycle always started with $5 \mathrm{mM}$ (labscale) and $2.5 \mathrm{mM}$ (outdoors) of extracellular N. This ensured a re-growth phase that continued until extracellular $\mathrm{N}$ was depleted again. At that point, a new TAG-accumulation phase followed until a new harvest was applied.

To harvest the culture at the right frequency (i.e. 1, 2 or 3 days after the onset of $\mathrm{N}$-depletion), preliminary tests were conducted to identify the time at which external $\mathrm{N}^{-\mathrm{NO}_{3}}{ }^{-}$concentration was zero. Typically, this was at $24 \mathrm{~h}$ after addition of nitrogen for both labscale and outdoor runs.

\section{Lab-scale cultivations}

Inoculum production and cultivation conditions Pre-cultures of Nannochloropsis sp. CCAP 211/78 were maintained in $250 \mathrm{~mL}$ Erlenmeyer flasks, which were placed in an orbital shaker incubator (Multitron, Infors HT, The Netherlands) at $120 \mathrm{rpm}$ under $2 \% \mathrm{CO}_{2}$-enriched headspace, $70 \%$ humidity. The flasks were continuously illuminated at a light intensity of $50 \mu \mathrm{mol}$ photons $\mathrm{m}^{-2} \mathrm{~s}^{-1}$ supplied by fluorescent lamps (TLD Reflex 36 W/840, Philips, The Netherlands). Two-week-old flask cultures were centrifuged $(780 \times \mathrm{g}, 5 \mathrm{~min})$ to remove remaining nutrients. Subsequently, cells were re-suspended in medium and inoculated in an airlift-loop photobioreactor with a light path of $20.7 \mathrm{~mm}, 1.9 \mathrm{~L}$ working volume and $0.08 \mathrm{~m}^{2}$ surface area (Labfors, Infors HT, 2010). Mass-flow controllers supplied 1.0 $\mathrm{L} \mathrm{min}^{-1}$ pressurized air for mixing. The $\mathrm{pH}$ was set at 7.5 and controlled by means of on-demand $\mathrm{CO}_{2}$ addition. A culture temperature of $25^{\circ} \mathrm{C}$ was maintained by water recirculation through water jackets that were in direct contact with the reactor cultivation chamber.

Each semi-continuous was stopped when three consecutive cycle repetitions were achieved (i.e. constant biomass concentration and TAG content at harvest), whereas the batch culture was kept for 10 days after the onset of $\mathrm{N}$-depletion.

Light supply For the first cultivation days, the ingoing light intensity was increased daily to keep the outgoing light at about $20 \mu \mathrm{mol}$ photons $\mathrm{m}^{-2} \mathrm{~s}^{-1}$. When the biomass concentration reached $0.7-0.9 \mathrm{~g} \mathrm{~L}^{-1}$, simulated day/night light rhythms of a midsummer day in the Netherlands were applied. By applying sinusoidal functions (Eq. 1), sunrise and sunset were simulated between $6 \mathrm{AM}$ and $10 \mathrm{PM}$. The light intensity gradually increased and reached the maximal value $\left(1500 \mu \mathrm{mol}\right.$ photons $\left.\mathrm{m}^{-2} \mathrm{~s}^{-1}\right)$ at $2 \mathrm{PM}$, after which it decreased to zero again.

$E(t)=\sin \left(\frac{t}{P} \cdot \pi\right) \cdot E_{\max }$

In which $t$ is the number of hours after sunrise (hours); $E_{\max }$ is the maximum light intensity ( $\mu \mathrm{mol}$ photons $\mathrm{m}^{-2} \mathrm{~s}^{-1}$ ), $P$ is the duration of the light period (hours).

\section{Outdoor cultivations}

Semi-continuous TAG production processes were also tested under outdoor conditions and their ground areal TAG productivities were compared to those achieved with batch cultivations. The two operational strategies were tested at AlgaePARC pilot facilities in Wageningen, the Netherlands (N 51 ${ }^{\circ} 59^{\prime} 45$ 88", 539'28.15") over different seasons (JulyOctober 2014) in identical vertically stacked horizontal tubular reactors (VRs; $170 \mathrm{~L}$ culture volume, $4.4 \mathrm{~m}^{2}$ ground area) which were simultaneously operated.

Inoculum production and cultivation conditions Pre-cultures were maintained in $250 \mathrm{~mL}$ Erlenmeyer flasks, as previously described. The flask cultures were used to inoculate a 20-L panel reactor with a 4-cm light path. Mass-flow controllers (Brooks Instrument LLC 0254, Hungary) supplied $1.50 \mathrm{~L} \mathrm{~min}^{-1}$ pressurized air for mixing, as well as $\mathrm{CO}_{2}$, which ensured a culture $\mathrm{pH}$ of 7.5. A temperature of $25^{\circ} \mathrm{C}$ was maintained by water recirculation through heating coils. An ingoing irradiance of $350 \mu \mathrm{mol}$ photons $\mathrm{m}^{-2} \mathrm{~s}^{-1}$ was supplied by fluorescence tubes placed in front of the reactor. From this flat panel reactor, a 1-week-old culture was used to inoculate an outdoor horizontal tubular reactor $(90 \mathrm{~L})$ (Benvenuti et al. 2015) operated as turbidostat at $3 \mathrm{~g} \mathrm{~L}^{-1}$. The biomass produced in this horizontal tubular reactor was used to inoculate the two identical VRs at similar starting biomass concentration $\left(0.5-0.8 \mathrm{~g} \mathrm{~L}^{-1}\right)$ in $\mathrm{N}$-free medium. One system was operated as batch and the other system as semi-continuous.

Operational settings for the outdoor reactors In the three outdoor tubular reactors (HR, VR1 and VR2), liquid velocity was set at $0.34 \mathrm{~m} \mathrm{~s}^{-1}$. To keep the $\mathrm{pH}$ at $7.5, \mathrm{CO}_{2}$ was added to the culture on demand. Temperature was kept between 20 and $30{ }^{\circ} \mathrm{C}$ by means of valves (Proportional Integral Differential regulation) that allowed either warm water $\left(\max .60^{\circ} \mathrm{C}\right)$ or chilled water $\left(8^{\circ} \mathrm{C}\right)$ to flow through a double-walled stripper, heating up or cooling down the culture until the set point was reached. A detailed description of the outdoor systems is given by Bosma et al. (2014) and Benvenuti et al. (2015). 
In both VRs, the residual nitrogen $(\mathrm{N})$ carried along with the inoculum supported about $0.5 \mathrm{~g} \mathrm{~L}^{-1}$ of newly formed biomass. In such a way, an initial biomass concentration for the TAG-accumulation phase of $1.0-1.5 \mathrm{~g} \mathrm{~L}^{-1}$ was reached. These initial biomass concentrations were chosen based on the findings of our previous study (Benvenuti et al. 2015) which identified it as the most suitable range to achieve high TAG productivities with Nannochloropsis sp. cultivated during summer and fall in outdoor vertically stacked tubular reactors in the Netherlands. Nitrogen was depleted from the medium within the first 2-4 days of cultivation in VRs, depending on the light received in this initial period. The moment of $\mathrm{N}$ depletion was considered as start of the N-starvation phase for the batch and of cycle \#0 for the semi-continuous cultivation.

The semi-continuous cultures were harvested and diluted to the set turbidity value (i.e. biomass concentration, $1 \mathrm{~g} \mathrm{~L}^{-1}$ ) by means of harvest and medium supply pumps (Bosma et al. 2014). Offline dry weight determinations were used to calibrate the response curve of turbidity. In all systems, a linear relation of dry weight concentrations and turbidity was found with high accuracy $\left(R^{2}>0.90\right)$.

For the semi-continuous cultivations, we aimed to harvest the culture at maximum ground areal TAG productivity. Because it was expected that more time is required when less light is available (Benvenuti et al. 2015), lower harvest frequencies were chosen when lower total irradiance was expected (Table 1).

The batch cultivation was kept for 10 days after N-depletion, after which the complete reactor was harvested and cleaned before repeating the process again. For the semicontinuous cultivation, the same harvest frequency was tested for about a month (Table 1). Exception was the semicontinuous run carried out in the second half of August (SC2). This run was stopped after 14 days because the biofilm formed in the tubes heavily impaired light penetration through the culture.

\section{Offline measurements}

Biomass samples were taken between $9 \mathrm{AM}$ and $10 \mathrm{AM}$ from the outdoor cultivations and at 2:00 PM from the lab-scale ones. Biomass concentration was measured daily (optical density $750 \mathrm{~nm}$ and dry weight), whereas cellular TAG content was measured only in harvested biomass. Dry weight was determined as described by Vejrazka et al. (2011) and cellular TAG content was analysed as described by Breuer et al. (2012) and Breuer et al. (2013a). Residual $\mathrm{N}^{-\mathrm{NO}_{3}}{ }^{-}$in the medium was measured daily, until its depletion, with an AQ2 nutrient analyser (Seal Analytical, USA) as described by Benvenuti et al. (2015).

\section{Calculations and definitions}

Time-averaged biomass and TAG productivity for batch and semi-continuous cultivations Time-averaged volumetric biomass and TAG productivity $\left(P_{j, \text { vol }}(t) ; \mathrm{g} \mathrm{L}^{-1}\right.$ day $\left.^{-1}\right)$ was calculated according to Eq. 2;

$P_{j, \mathrm{vol}}(t)=\frac{\sum_{t=0}^{t}\left(H_{j}\right)}{V_{\mathrm{R}} \cdot t_{i}}$

In which $H_{j}(\mathrm{~g})$ is the amount of biomass or TAGs present in the harvest (for batch cultivations, $H_{j}$ was calculated with the total reactor harvest); $V_{\mathrm{R}}$ is the reactor volume $(\mathrm{L}) ; t_{i}$ is any time point during cultivation (days).

To calculate TAG productivity of the batch cultivations,

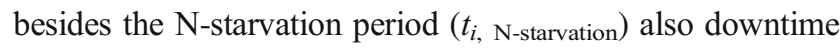
(i.e. reactor cleaning and startup; $t_{\text {downtime}}$ ) and inoculum production (i.e. amount of biomass present at the moment of N-

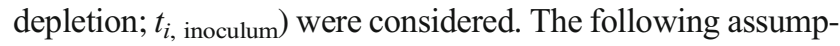
tions were made: downtime was fixed to 1 day, and inoculum was produced at a certain biomass yield per mole photons in a hypothetical "growth" reactor operated in continuous mode in nitrogen replete conditions. This hypothetical growth reactor supplied biomass to the batch reactor, which was subsequently
Table 1 Operational period, corresponding time-averaged light intensity $\left(E_{\text {ground }}(t)\right)$, days from $\mathrm{N}$-depletion at which harvest was applied and number of harvest events are reported. $S C$, semi-continuous; $B$, batch

\begin{tabular}{lllll}
\hline Run & Operational period (2014) & $\begin{array}{l}E_{\text {ground }}(t)(\mathrm{mol} \\
\left.\text { photons } \mathrm{m}^{-2} \text { day }^{-1}\right)\end{array}$ & $\begin{array}{l}\text { \# days harvest } \\
\text { from N-depletion }\end{array}$ & $\begin{array}{l}\text { \# harvest } \\
\text { events }\end{array}$ \\
\hline $\mathrm{SC} 1$ & 16 July-8 August & 37 & 1 & 9 \\
$\mathrm{~B} 1 a$ & 12-24 July & 39 & 10 & 1 \\
$\mathrm{~B} 1 b$ & 26 July-6 August & 36 & 9 & 1 \\
$\mathrm{SC} 2$ & 19-28 August & 26 & 2 & 3 \\
$\mathrm{~B} 2$ & 15-27 August & 23 & 10 & 1 \\
$\mathrm{SC} 3$ & 10 September-6 October & 20 & 3 & 5 \\
$\mathrm{~B} 3 a$ & 3-17 September & 24 & 10 & 1 \\
$\mathrm{~B} 3 b$ & 20 September-4 October & 18 & 10 & 1 \\
\hline
\end{tabular}


subjected to $\mathrm{N}$-starvation to trigger TAG accumulation. Hence, $t_{i}$, inoculum was calculated using the average light supplied rate over the cultivation period (Table 2 ) and an average biomass yield per mole photons of $0.59 \mathrm{~g} \mathrm{~mol}^{-1}$ photons. This yield was found for the most efficient outdoor biomass production system (i.e. flat panel PBR operated with a daily dilution rate of $0.27 \mathrm{day}^{-1}$ over a period of 36 days) at AlgaePARC pilot facility, the Netherlands (de Vree et al. 2015). Thus, the time considered for calculations of batch time-averaged productivities is defined as $t_{i}$, batch $=t$ downtime $+t_{i \text {, inoculum }}+t_{i, \mathrm{~N} \text {-starvation }}$.

For semi-continuous cultivations, both the startup procedure and the inoculum production will take place only at the beginning of the process and this time is negligible for longterm runs. Additionally, for the semi-continuous productivity, the first harvest (cycle \#0) was not taken into account. As it was produced from N-replete biomass, it was not representative for a long-term operation. Thus, the start of cycle \#1 was considered as start of the semi-continuous cultivations.

Time-averaged ground areal biomass and TAG productivity For the outdoor runs, time-averaged ground areal biomass or TAG productivity $\left(P_{j}\right.$, ground $(t) ; \mathrm{g} \mathrm{m}^{-2}$ day $\left.^{-1}\right)$ was calculated multiplying the time-averaged volumetric productivities by the reactor volume $(170 \mathrm{~L})$-to-ground area $\left(4.4 \mathrm{~m}^{2}\right)$ ratio.

\section{Biomass and TAG productivity over a semi-continuous} cycle For the semi-continuous cultivations, biomass and TAG productivity over a cycle $\left(P_{j \text {, cycle }} ; \mathrm{g} \mathrm{m}^{-2}\right.$ day $\left.{ }^{-1}\right)$ is also discussed. $P_{j \text {, cycle was calculated by dividing the harvested }}$ biomass or TAGs $\left(H_{j} ; \mathrm{g}\right)$ at the end of the cycle by the reactor ground area $\left(\mathrm{m}^{2}\right)$ and cycle duration (days).

Time-averaged biomass and TAG yields per mole photons Time-averaged biomass $\left(Y_{x, \mathrm{ph}}(t) ; \mathrm{g} \mathrm{mol}^{-1}\right.$ photons $)$ and TAG $\left(Y_{\mathrm{TAG}, \mathrm{ph}}(t) ; \mathrm{g} \mathrm{mol}^{-1}\right.$ photons) yield per mole photons were calculated by dividing the time-averaged ground areal biomass or TAG productivity by the time-averaged irradiance $\left(E_{\text {ground }}(t)\right.$; mol photons $\mathrm{m}^{-2}$ day $^{-1}$ ) received on ground area during the considered time interval.

\section{Results}

\section{Lab-scale cultivations}

Lab-scale batch cultivations Nitrogen $(\mathrm{N})$ depletion (day 4) triggered accumulation of TAGs, which, within 24 hours, increased fourfold (Fig. 2). TAG content steadily increased until stabilizing at about $0.39 \mathrm{~g} \mathrm{~g}^{-1}$ by the end of the cultivation. Maximum time-averaged volumetric TAG productivity $\left(P_{\mathrm{TAG}, \mathrm{vol}, \max }(t) ; 0.23 \mathrm{~g} \mathrm{~L}^{-1}\right.$ day $\left.^{-1}\right)$ and yield per mole photons $\left(Y_{\mathrm{TAG}, \mathrm{ph}, \max }(t) ; 0.10 \mathrm{~g} \mathrm{~mol}^{-1}\right.$ photons) were observed after 4 days of $\mathrm{N}$-depletion (day 8) (Table 3 ). At $P_{\mathrm{TAG}}$, vol, max $(t)$, cellular TAG content was $0.35 \mathrm{~g} \mathrm{~g}^{-1}$.

Lab-scale semi-continuous cultivations Each semicontinuous run was stopped after three consecutive and constant cycle repetitions (Fig. 3 and Table 3) (i.e. steady-state cycles; \#1-\#3). At the harvest of the constant cycle repetitions, biomass concentrations and TAG contents were equal for the different cycles (standard deviation within $5 \%$ of average).

TAG productivity $\left(0.14-0.21 \mathrm{~g} \mathrm{~mol}^{-1}\right.$ photons) increased with decreasing cycle duration, whereas an opposite trend was observed for TAG content, which ranged from 0.22 to $0.33 \mathrm{~g} \mathrm{~g}^{-1}$ (Table 3).

\section{Outdoor cultivations}

Outdoor batch cultivations For the five outdoor batch cultivations, N-depletion occurred at $1.04 \pm 0.09 \mathrm{~g} \mathrm{~L}^{-1}$, after which TAG accumulation commenced.

The highest maximum time-averaged TAG yield per mole photons $\left(Y_{\mathrm{TAG}, \mathrm{ph}, \max }(t)\right.$; i.e. optimal harvest time for the
Table 2 Time for inoculum production $\left(t_{\text {inoculum }}\right)$, average light supply rate, reactor area $\left(A_{\mathrm{R}}\right)$ and inoculum concentration $\left(C_{x}\right.$, inoculum) for the lab-scale and outdoor batch runs

\begin{tabular}{llllllll}
\hline & $\mathrm{B} I$, lab-scale & $\mathrm{B} I$, lab-scale & $\mathrm{B} 1 a_{\text {, out }}$ & $\mathrm{B} 1 b$, out & $\mathrm{B} 2$, out & $\mathrm{B} 3 a$, out & $\mathrm{B} 3 b$, out \\
\hline $\begin{array}{l}t_{\text {inoculum }} \text { (days) } \\
\begin{array}{c}\text { Average light supply rate } \\
\left(\mathrm{mol} \mathrm{photons} \mathrm{day}^{-1}\right)\end{array}\end{array}$ & 1.4 & 1.3 & 1.9 & 2.0 & 3.1 & 2.7 & 3.3 \\
$A_{\mathrm{R}}{ }^{\mathrm{a}}\left(\mathrm{m}^{2}\right)$ & 0.08 & 0.4 & 172 & 160 & 102 & 105 & 78 \\
$C_{x, \text { inoculum }}\left(\mathrm{g} \mathrm{L}^{-1}\right)$ & 1.92 & 1.84 & 4.4 & 4.4 & 4.4 & 4.4 & 4.4 \\
\hline
\end{tabular}

${ }^{\mathrm{a}} A_{\mathrm{R}}$ is the illuminated reactor surface area for the lab-scale systems and the reactor ground area for the outdoor systems 


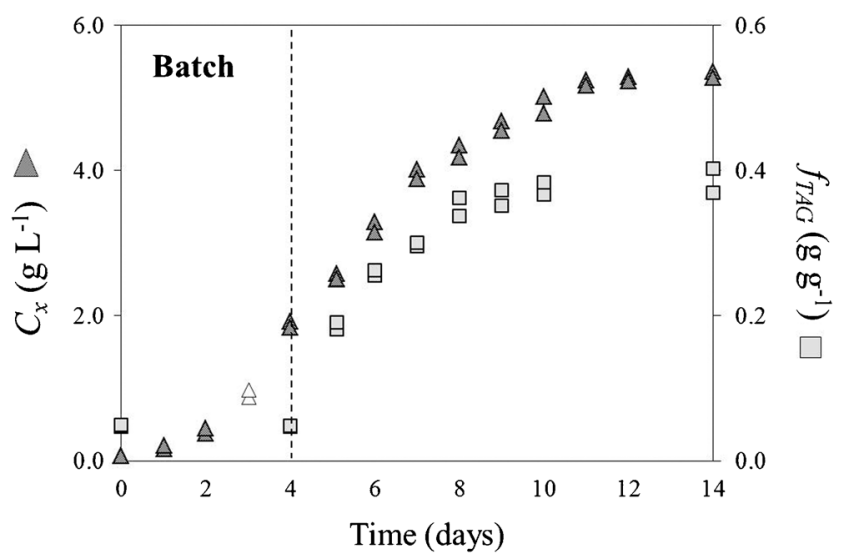

Fig. 2 Time-evolution of biomass concentration and TAG content for the duplicate lab-scale batch cultivations. Empty symbols represent the day at which light intensity was switched to set point. The dotted line indicates day zero of nitrogen-starvation

batch), corresponding to $0.09 \mathrm{~g} \mathrm{~mol}^{-1}$ photons, was observed for the runs $\mathrm{B} 2$ and $\mathrm{B} 3 a$ (Table 4), which were performed at intermediate irradiance (23-24 mol photons $\mathrm{m}^{-2}$ day $\left.^{-1}\right)$. At $Y_{\text {TAG, ph, max }}(t)$, TAG content was $0.15-0.21 \mathrm{~g} \mathrm{~g}^{-1}$.

Outdoor semi-continuous cultivations In contrast with the lab-scale semi-continuous experiments, the biomass concentration at harvest greatly varied for the outdoor semicontinuous runs $(1.18-1.63,1.30-1.53$ and $1.21-$ $1.52 \mathrm{~g} \mathrm{~L}^{-1}$ ) for $\mathrm{SC} 1, \mathrm{SC} 2$ and $\mathrm{SC} 3$, respectively (Fig. 4; symbols) because of varying light conditions (Fig. 4; bars). Therefore, constant cycle repetitions were not achieved. In $\mathrm{SC} 1$ and $\mathrm{SC} 2$, nitrogen $(\mathrm{N})$ was generally consumed within $24 \mathrm{~h}$ from addition. However, at lower total irradiance, i.e. SC3, $\mathrm{N}$ was depleted from the medium only after 2 or 3 days from addition. This

Table 3 Time-averaged volumetric biomass productivity $\left(P_{x}\right.$, vol, cycle $(t))$ and TAG $\left(P_{\text {TAG, vol, cycle }}(t)\right)$ productivities, time-averaged biomass $\left(Y_{x, \text { ph, cycle }}(t)\right)$ and TAG $\left(Y_{\mathrm{TAG}, \mathrm{ph} \text {, cycle }}(t)\right)$ yields per mole photons over cycle and TAG content $\left(f_{\text {TAG }}\right)$ for the lab-scale batch and semi-continuous resulted in longer re-growth phases, which strongly reduced the time-averaged biomass and TAG productivities and yields per mole photons (Table 5). Average TAG contents at harvest were low $(10-13 \% w / w)$ and similar among the different semi-continuous runs (Table 5). Throughout a single semi-continuous run, TAG yield per mole photons $\left(Y_{\mathrm{TAG}}, \mathrm{ph}\right.$, cycle $)$ greatly differed over the cycles (Supplementary material 2).

\section{Discussion}

Batch vs. semi-continuous TAG production at lab-scale The TAG productivity obtained for the constant semicontinuous cycle repetitions (\#1-\#3) is compared with the maximum time-averaged batch TAG productivity (i.e. the productivity at the optimal harvest time for the batch; $P_{\mathrm{TAG}}$ max $(t))$. Noteworthy, the TAG productivity obtained with shortest semi-continuous cycle $\left(\mathrm{SC} 1 ; 0.21 \mathrm{~g} \mathrm{~L}^{-1}\right.$ day $^{-1}$ ) was similar to the maximum TAG productivity of the batch process (i.e. optimal harvest time for the batch; $0.23 \mathrm{~g} \mathrm{~L}^{-1}$ day $^{-1}$ ) (Table 3). Although, SC1 resulted in a lower TAG content $\left(0.22 \mathrm{~g} \mathrm{~g}^{-1}\right)$ compared to the batch $\left(0.35 \mathrm{~g} \mathrm{~g}^{-1}\right)$, much higher biomass productivity was obtained with $\mathrm{SC} 1$. About $0.73 \mathrm{~g} \mathrm{~L}^{-1} \mathrm{day}^{-1}$ of non-TAG-biomass was produced in $\mathrm{SC} 1$, whereas $0.43 \mathrm{~g} \mathrm{~L}^{-1}$ day $^{-1}$ was produced in the batch. Several cellular components can contribute to the non-TAGfraction of the biomass, such as non-acyl lipids, glyco- and phospholipids, sugars and proteins (Wang and Wang 2012; Bondioli et al. 2012). For instance, with the calculated intracellular nitrogen content (Supplementary material 1), it is possible to estimate the mass fraction and productivity of proteins (Breuer et al. 2012) that, besides TAGs, represent one of the major biomass constituents with a high economic value

runs. Values for the each batch duplicate culture are shown. For the semicontinuous runs, mean and standard deviation are reported $(n=3)$. SC1, SC2 and SC3 were harvested every 1, 2 and 3 days after nitrogen-depletion, respectively

Lab-scale runs

\begin{tabular}{|c|c|c|c|c|}
\hline & Batch $^{\mathrm{a}}$ & $\mathrm{SC} 1$ & $\mathrm{SC} 2$ & $\mathrm{SC} 3$ \\
\hline$P_{x, \text { vol }}(t)\left(\mathrm{g} \mathrm{L}^{-1}\right.$ day $\left.^{-1}\right)$ & $\begin{array}{l}0.68 \\
0.66\end{array}$ & $0.94 \pm 0.02$ & $0.57 \pm 0.02$ & $0.43 \pm 0.01$ \\
\hline$Y_{x, \mathrm{ph}}(t)\left(\mathrm{g} \mathrm{mol}^{-1}\right.$ photons $)$ & $\begin{array}{l}0.29 \\
0.28\end{array}$ & $0.40 \pm 0.01$ & $0.25 \pm 0.01$ & $0.19 \pm 0.00$ \\
\hline$f_{\mathrm{TAG}}\left(\mathrm{g} \mathrm{g}^{-1}\right)$ & $\begin{array}{l}0.34 \\
0.36\end{array}$ & $0.22 \pm 0.00$ & $0.28 \pm 0.01$ & $0.33 \pm 0.01$ \\
\hline$P_{\mathrm{TAG}, \mathrm{vol}}(t)\left(\mathrm{g} \mathrm{L}^{-1}\right.$ day $\left.^{-1}\right)$ & $\begin{array}{l}0.23 \\
0.24\end{array}$ & $0.21 \pm 0.01$ & $0.16 \pm 0.00$ & $0.14 \pm 0.00$ \\
\hline$Y_{\mathrm{TAG}, \mathrm{ph}}(t)$ ( $\mathrm{g} \mathrm{mol}^{-1}$ photons $)$ & $\begin{array}{l}0.10 \\
0.10\end{array}$ & $0.09 \pm 0.00$ & $0.07 \pm 0.00$ & $0.06 \pm 0.00$ \\
\hline
\end{tabular}

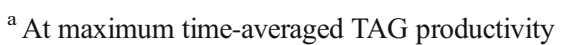


a

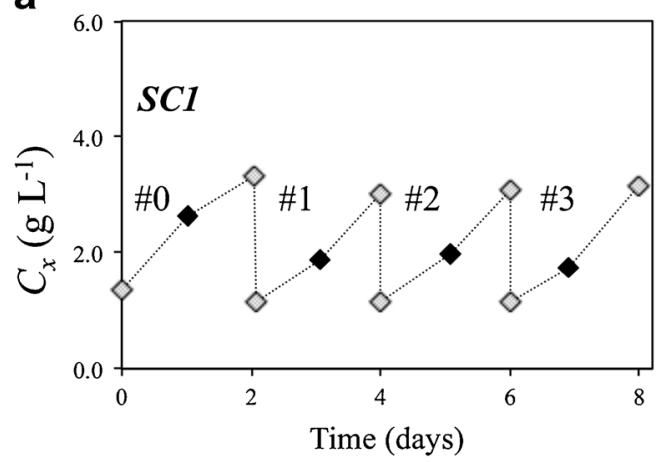

b

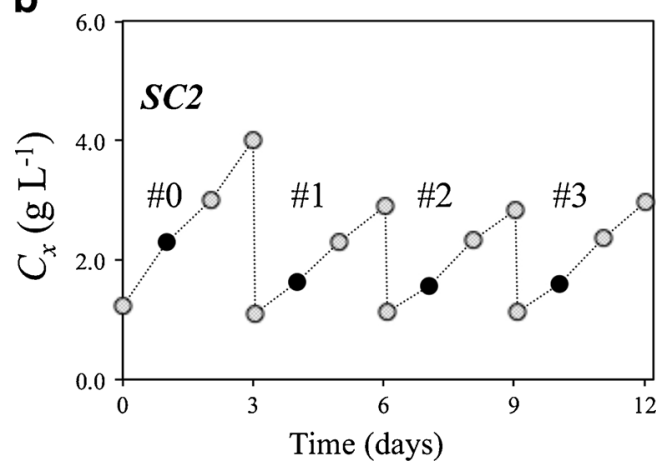

C

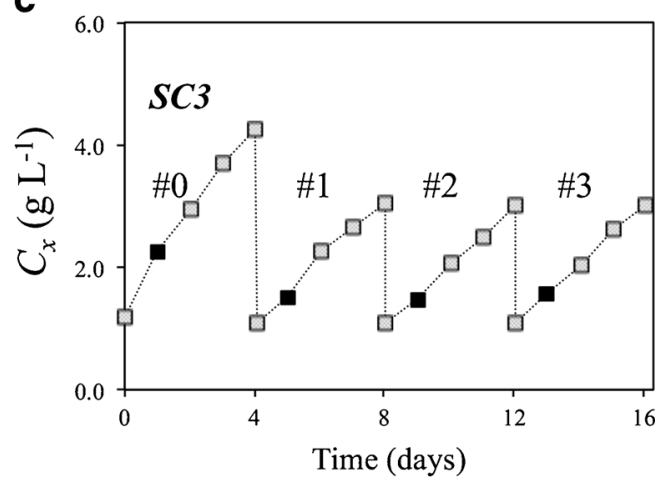

Fig. 3 Time-evolution of biomass concentration for the lab-scale semicontinuous cultivations (SC1, SC2 and $\mathrm{SC} 3$ ). $\mathrm{SC} 1, \mathrm{SC} 2$ and $\mathrm{SC} 3$ were harvested every 1, 2 and 3 days after nitrogen-depletion, respectively. Black symbols indicate biomass concentration at N-depletion. Lines are drawn only for illustrative purposes

Table 4 Time-averaged ground areal biomass $\left(P_{x}\right.$, ground $\left.(t)\right)$ and TAG $\left(P_{\mathrm{TAG}, \text { ground }}(t)\right)$ productivities, time-averaged biomass $\left(Y_{x, \mathrm{ph}}(t)\right)$ and TAG $\left(Y_{\mathrm{TAG}}\right.$, ph, max $\left.(t)\right)$ yields per mole photons, TAG content $\left(f_{\mathrm{TAG}}\right)$ and time-
(Wijffels et al. 2010). The batch cultivations resulted in an estimated protein content of $0.21 \mathrm{~g} \mathrm{~g}^{-1}$ with a productivity of $0.14 \mathrm{~g} \mathrm{~L}^{-1}$ day $^{-1}$. SC1 yielded similar protein contents $\left(0.24 \mathrm{~g} \mathrm{~g}^{-1}\right)$ but higher productivities $\left(0.22 \mathrm{~g} \mathrm{~L}^{-1}\right.$ day $\left.^{-1}\right)$. Therefore, if only the TAG fraction of the biomass is used, the lower TAG contents obtained with semi-continuous processes will likely result in higher costs for downstream operations (harvesting, dehydration, extraction) (Molina-Grima et al. 2003). Semi-continuous TAG production may become cost effective if a biorefinery approach is pursued and the whole biomass is valorized (Wijffels et al. 2010). For this, mild cell disruption techniques (e.g. pulsed electric field) and separation technologies (e.g. ionic liquids), which are able to both separate hydrophobic and hydrophilic compounds, should be adopted (Vanthoor-Koopmans et al. 2013).

When comparing the TAG yields per mole photons obtained in this study with those reported in literature, higher values were found for Chlorella and Scenedesmus cultivations in flat panel reactors to which lower $\left(175-500 \mu \mathrm{mol}\right.$ photons $\left.\mathrm{m}^{-2} \mathrm{~s}^{-1}\right)$ and continuous light intensities were supplied (Han et al. 2013; Breuer et al. 2014; Mulders et al. 2014). Besides that the TAG yield per mole photons of different species differs substantially (Griffiths and Harrison 2009; Breuer et al. 2012; Benvenuti et al. 2014), the lower yields found in our study under day/night cycles may be explained by the very high incident light intensities experienced during the central hours of the day (up to $1500 \mu \mathrm{mol}$ photons $\mathrm{m}^{-2} \mathrm{~s}^{-1}$ ). It is indeed known that very high light intensities result in substantial yield losses, whereas lower incident light intensities are beneficial for TAG production (Breuer et al. 2013b). Additionally, during the night, energy storage metabolites are likely be respired to satisfy the maintenance energy demand (Torzillo et al. 1991; Fábregas et al. 2002), thus further decreasing the TAG yield per mole photons.

Batch vs. semi-continuous TAG production in outdoor photobioreactors As constant cycle repetitions were not achieved with the semi-continuous runs (Fig. 4), outdoor batch and semi-continuous TAG production

averaged light intensity $\left(E_{\text {ground }}(t)\right)$ for the outdoor batch runs (B1 $a, \mathrm{~B} 1 b, \mathrm{~B} 2$, $\mathrm{B} 3 a, \mathrm{~B} 3 b)$. In parentheses, the day of nitrogen-starvation at which maximum time-averaged TAG yield per mole photons was found

Outdoor batch runs

\begin{tabular}{|c|c|c|c|c|c|}
\hline & $\mathrm{B} 1 a$ & $\mathrm{~B} 1 b$ & B2 & $\mathrm{B} 3 a$ & $\mathrm{~B} 3 b$ \\
\hline$P_{x, \text { ground }}(t)^{\mathrm{a}}\left(\mathrm{g} \mathrm{m}^{-2}\right.$ day $\left.^{-1}\right)$ & 11.85 & 9.23 & 8.99 & 11.45 & 6.33 \\
\hline$Y_{x, \mathrm{ph}}(t)^{\mathrm{a}}\left(\mathrm{g} \mathrm{mol}^{-1}\right.$ photons $)$ & 0.36 & 0.28 & 0.39 & 0.46 & 0.40 \\
\hline$f_{\mathrm{TAG}}{ }^{\mathrm{a}}\left(\mathrm{g} \mathrm{g}^{-1}\right)$ & 0.21 & 0.21 & 0.23 & 0.20 & 0.15 \\
\hline$P_{\mathrm{TAG}, \text { ground }}(t)^{\mathrm{a}}\left(\mathrm{g} \mathrm{m}^{-2} \mathrm{day}^{-1}\right)$ & 2.46 & 1.91 & 2.06 & 2.26 & 0.97 \\
\hline$Y_{\mathrm{TAG}, \mathrm{ph}, \max }(t)\left(\mathrm{g} \mathrm{mol}^{-1}\right.$ photons $)$ & $0.07(3)$ & $0.06(3)$ & $0.09(6)$ & $0.09(5)$ & $0.06(4)$ \\
\hline$E_{\text {ground }}(t)\left(\mathrm{mol}\right.$ photons $\mathrm{m}^{-2}$ day $\left.^{-1}\right)$ & 39 & 36 & 23 & 24 & 18 \\
\hline
\end{tabular}

${ }^{\text {a }}$ At maximum time-averaged TAG yield per mole photons 

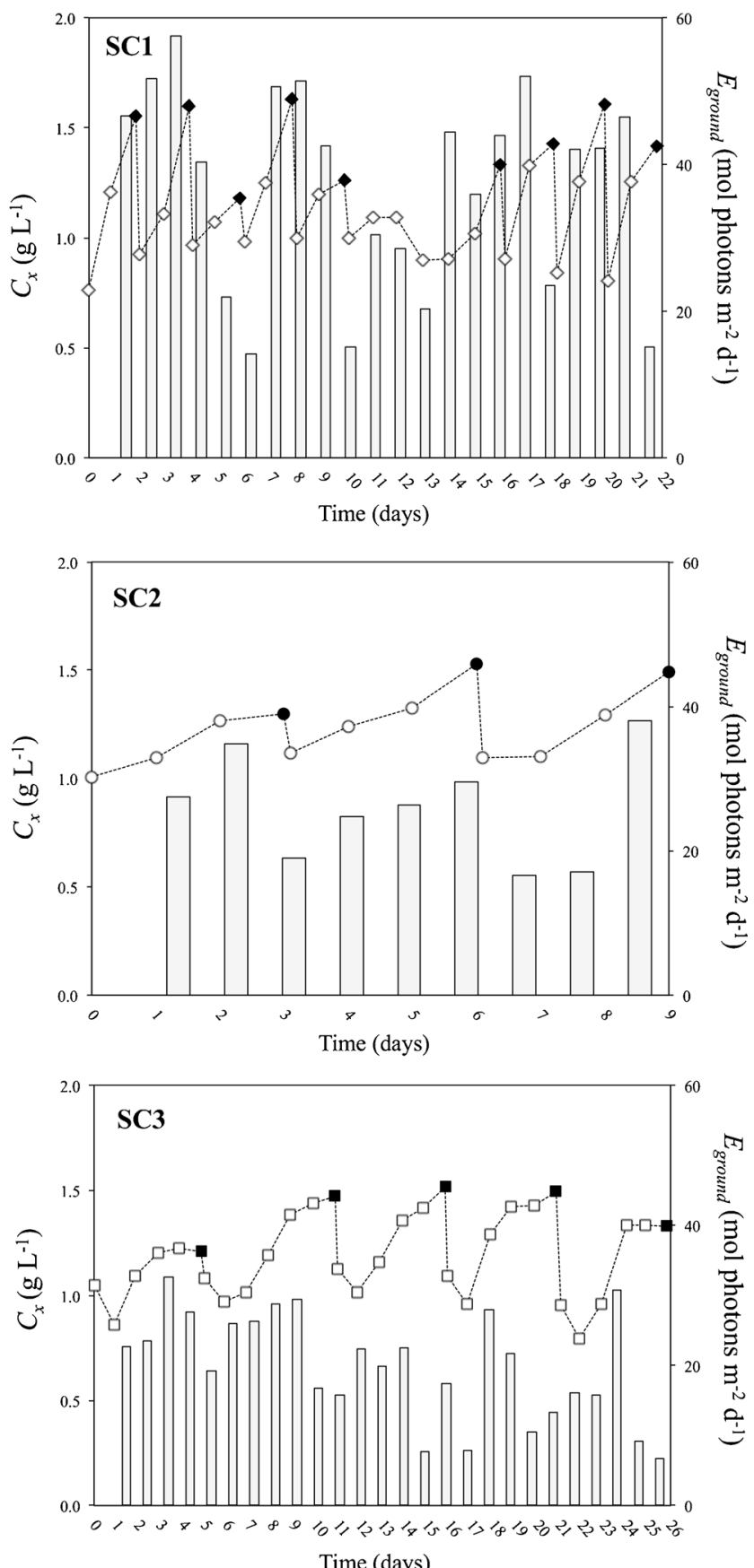

Fig. 4 Time-evolution of biomass concentration $\left(C_{x} ;\right.$ symbols $)$ and daily irradiance on ground area $\left(E_{\text {ground }}\right.$; bars $)$ for the outdoor semi-continuous runs. SC1, SC2 and SC3 were harvested every 1, 2 and 3 days after nitrogen-depletion, respectively. Black symbols correspond to days at which a harvest was applied. Lines are drawn only for illustrative purposes

processes are compared on the TAG productivity calculated over the same period (Fig. 5). The period considered for comparing the batch with the corresponding semi-continuous process is equivalent to the duration of the semi-continuous cultivation. It is assumed that, during that period, the batch culture is harvested when the time-averaged TAG yield per mole photons is maximal (i.e. optimal harvest time) and started again (section 2.4.1). The batch productivities were re-calculated over 22 days (for $\mathrm{B} 1 a$ and $\mathrm{B} 1 b$ ), 9 days (for $\mathrm{B} 2$ ) and 26 days (for $\mathrm{B} 3 a, \mathrm{~B} 3 b$ ) and then compared to the timeaveraged TAG productivities of the semi-continuous process. By harvesting the batch cultures when the time-averaged TAG productivity is maximal, much higher TAG productivities (and contents) can be achieved with batch than with semi-continuous cultivations (Fig. 5). In the latter ones, likely, too much nitrogen was present in the system for the given irradiance and cycle duration.

The highest TAG yield per mole photons achieved with our semi-continuous cultivations $\left(Y_{\mathrm{TAG}}\right.$, ph, cycle of $0.04 \mathrm{~g} \mathrm{~mol}^{-1}$ photons corresponding to a $P_{\mathrm{TAG}}$, cycle of $2.2 \mathrm{~g} \mathrm{~m}^{-2}$ day $^{-1}$ for SC1) was about 1.5 -fold lower than the highest $Y_{\mathrm{TAG}}$, ph, cycle $\left(0.06 \mathrm{~g} \mathrm{~mol}^{-1}\right.$ photons corresponding to a $P_{\mathrm{TAG}}$, cycle of $7.7 \mathrm{~g} \mathrm{~m}^{-2}$ day $^{-1}$ ) reported by Bondioli et al. (2012) for a semi-continuous cultivation (44\% daily harvest) of Nannochloropsis sp. This discrepancy mainly relies on the higher degree of stress applied to cells in the study of Bondioli et al. (2012) compared to our semi-continuous cultivations. Firstly, in their study, no nitrogen $(\mathrm{N})$ was re-supplied after harvest. Secondly, the culture likely experienced higher light availabilities. Because of the higher total irradiance and the reactor used by Bondioli et al. (2012) (i.e. single flat panel not subjected to mutual shadowing from other panels, as was the case for the tubes used in our study), their culture received a higher amount of light. Thus, the combination of lower nitrogen in the system and higher light availabilities resulted in the higher $Y_{\mathrm{TAG}}$, ph, cycle reported by Bondioli et al. (2012).

Noteworthy, the maximum time-averaged TAG yields per mole photons (Table 4) obtained in our outdoor batch cultivations are comparable with the ones found by Quinn et al. (2012) with the same species cultivated year-round in outdoor flat panel reactors in Colorado, USA.

Outlook on future research To certainly assess whether semi-continuous TAG production represents an effective alternative to batch processes, several aspects should be further investigated.

Outdoors, focus should be put on the applied stress pressure, and both nitrogen (N) supply and harvest frequency should be adjusted based on the expected total irradiance. Accurate production models could contribute in identifying 
Table 5 Time-averaged ground areal biomass $\left(P_{x}\right.$, ground $\left.(t)\right)$ and TAG $\left(P_{\mathrm{TAG}, \text { ground }}(t)\right)$ productivities, time-averaged biomass $\left(Y_{x, \mathrm{ph}}(t)\right)$ and TAG $\left(Y_{\text {TAG, }}\right.$ ph, max $\left.(t)\right)$ yields per mole photons, TAG content $\left(f_{\text {TAG }}\right)$ and time-averaged light intensity $\left(E_{\text {ground }}(t)\right)$ for the outdoor semi- continuous (SC) runs. SC1, SC2 and SC3 were harvested every 1,2 and 3 days after nitrogen-depletion, respectively. For $f_{\text {TAG }}$, mean and standard deviation are reported (SC1, $n=9 ; \mathrm{SC} 2, n=3 ; \mathrm{SC} 3, n=5$ )

Outdoor semi-continuous runs

\begin{tabular}{llll}
\hline & $\mathrm{SC} 1$ & $\mathrm{SC} 2$ & $\mathrm{SC} 3$ \\
\hline$P_{x, \text { ground }}(t)\left(\mathrm{g} \mathrm{m}^{-2}\right.$ day $\left.^{-1}\right)$ & 8.13 & 4.77 & 2.66 \\
$Y_{x, \text { ph }}(t)\left(\mathrm{g} \mathrm{mol}^{-1}\right.$ photons $)$ & 0.22 & 0.18 & 0.13 \\
$f_{\text {TAG }}\left(\mathrm{g} \mathrm{g}^{-1}\right)$ & $0.10 \pm 0.05$ & $0.13 \pm 0.02$ & $0.13 \pm 0.01$ \\
$P_{\text {TAG, ground }}(t)\left(\mathrm{g} \mathrm{m}^{-2}\right.$ day $\left.^{-1}\right)$ & 0.85 & 0.59 & 0.35 \\
$Y_{\text {TAG, ph }}(t)\left(\mathrm{g} \mathrm{mol}^{-1}\right.$ photons $^{-1}$ & 0.022 & 0.023 & 0.018 \\
$E_{\text {ground }}(t)\left(\mathrm{mol} \mathrm{photons}^{-2}\right.$ day $\left.^{-1}\right)$ & 37 & 26 & 20 \\
\hline
\end{tabular}

optimal "nitrogen-to-light ratios". These models should be developed based on dedicated sets of lab-scale experiments, where the dependency of both N-supply and harvest frequency from irradiance is investigated under well-defined light regimes. Subsequently, the models should be validated outdoors under varying light conditions. Regardless of the operational strategy, daily measurable parameters such as the irradiance, the biomass concentration (e.g. turbidity) and the cellular TAG content (e.g. Nile Red fluorescence (Chen et al. 2009) or FTIR spectroscopy (Miglio et al. 2013; Mayers et al. 2013)) should be used to implement the optimal operational settings in such a way that harvest is always appropriately timed for any given $\mathrm{N}$-supply and any given irradiance.

Additionally, to operate an optimized semi-continuous process, a full understanding of cell recovery mechanisms upon $\mathrm{N}$-replenishment is required as these may greatly affect the

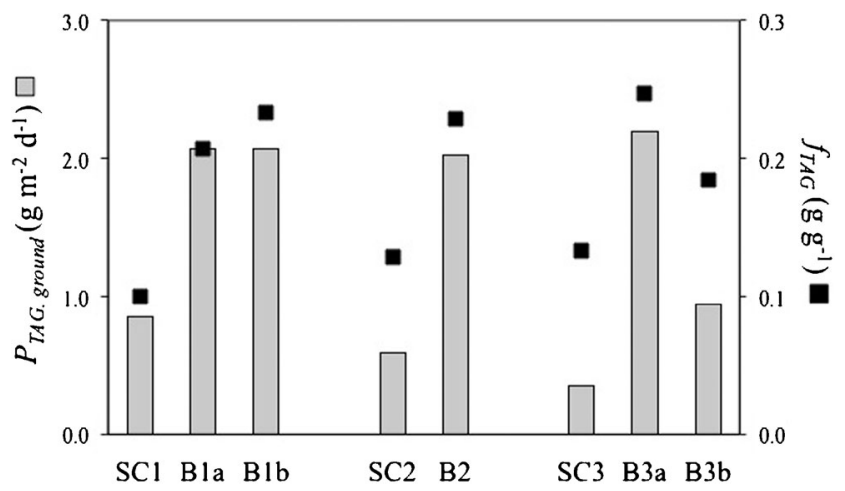

Fig. 5 TAG content $\left(f_{\text {TAG }}\right)$ and time-averaged ground areal TAG productivity $\left(P_{\mathrm{TAG}}\right.$, ground $)$ of the outdoor batch $(\mathrm{B} 1 a, \mathrm{~B} 1 b, \mathrm{~B} 2, \mathrm{~B} 3 a, \mathrm{~B} 3 b)$ and semi-continuous ( $\mathrm{SC} 1, \mathrm{SC} 2, \mathrm{SC} 3$ ) cultivations. For process comparison,

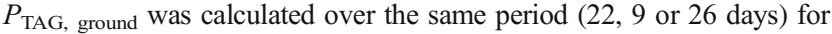
both operational strategies productivity of the entire process. Only few research papers have been published on this topic (Siaut et al. 2011; Fernandes et al. 2013; Mulders et al. 2015). In these studies, cells were replenished with an excess of nitrogen after a long $\mathrm{N}$ starvation period (>7-15 days). It was found that the TAGs, which were accumulated during the $\mathrm{N}$-starvation period, were entirely respired within 2 days from N-replenishment to fuel the recovery process. However, the extent of TAG degradation and its rate depend on several factors such as species-specific photosynthetic responses to N-starvation and recovery, amount of re-supplied nitrogen, harvest frequency and harvest volume. Therefore, the dependency of recovery mechanisms on these factors has to be fully understood before an optimal semi-continuous process can be designed.

Finally, as also speculated by Mulders et al. (2015), higher outdoor semi-continuous TAG productivities could possibly be achieved by resupplying the nitrogen around sunset. Culture recovery would then occur at night (Siaut et al. 2011; Prribyl et al. 2013), thereby enhancing TAG production during the light period.

Conclusions The lab-scale experiments demonstrated that semi-continuous strategies could achieve similar TAG productivities compared to batch processes. Additionally, it was shown that semi-continuous cultivations can potentially make TAG production cost effective by valorising also non-TAGcompounds provided that biorefinery of the whole biomass is pursued. Contrarily, further optimization of outdoor semicontinuous strategies is necessary as these were always outcompeted by the batch process. In particular, attention should be given to the chosen semi-continuous operational settings (e.g. nitrogen supply and harvest frequency) as these, together with the total irradiance, determine the applied stress pressure and thus, the productivity of the process. 
Acknowledgments The authors would like to thank the Ministry of Economic Affairs, Agriculture and Innovation and Province of Gelderland, and Biosolar Cells, BASF, BioOils, Cellulac, Drie Wilgen Development, DSM, Exxon Mobil, GEA Westfalia Separator, Heliae, Neste, Nijhuis, Paques, Proviron, Roquette, SABIC, Simris Alg, Staatsolie Suriname, Synthetic Genomics, TOTAL and Unilever for the financial support of the AlgaePARC research program.

Open Access This article is distributed under the terms of the Creative Commons Attribution 4.0 International License (http:// creativecommons.org/licenses/by/4.0/), which permits unrestricted use, distribution, and reproduction in any medium, provided you give appropriate credit to the original author(s) and the source, provide a link to the Creative Commons license, and indicate if changes were made.

\section{References}

Benvenuti G, Bosma R, Cuaresma M, Janssen M, Barbosa MJ, Wijffels RH (2014) Selecting microalgae with high lipid productivity and photosynthetic activity under nitrogen starvation. J Appl Phycol 27:1425-1431

Benvenuti G, Bosma R, Klok AJ, LAmers PP, Barbosa MJ, Wijffels RH (2015) Microalgal triacylglycerides production in outdoor batchoperated tubular PBRs. Biotechnol Biofuels 8:100

Bona F, Capuzzo A, Franchino M, Maffei ME (2014) Semicontinuous nitrogen limitation as convenient operation strategy to maximize fatty acid production in Neochloris oleoabundans. Algal Res 5:1-6

Bondioli P, Della Bella L, Rivolta G, Chini Zittelli G, Bassi N, Rodolfi L, Casini D, Prussi M, Chiaramonti D, Tredici MR (2012) Oil production by the marine microalgae Nannochloropsis sp. F\&M-M24 and Tetraselmis suecica F\&M-M33. Bioresour Technol 114:567-572

Bosma R, de Vree JH, Slegers PM, Janssen M, Wijffels RH, Barbosa MJ (2014) Design and construction of the microalgal pilot facility AlgaePARC. Algal Res 6 Part B:160-169

Breuer G, Lamers PP, Martens DE, Draaisma RB, Wijffels RH (2012) The impact of nitrogen starvation on the dynamics of triacylglycerol accumulation in nine microalgae strains. Bioresour Technol 124: $217-226$

Breuer G, Evers WAC, de Vree JH, Kleinegris DMM, Martens DE, Wijffels RH, Lamers PP (2013a) Analysis of fatty acid content and composition in microalgae. J Vis Exp 80:e50628

Breuer G, Lamers PP, Martens DE, Draaisma RB, Wijffels RH (2013b) Effect of light intensity, $\mathrm{pH}$, and temperature on triacylglycerol (TAG) accumulation induced by nitrogen starvation in Scenedesmus obliquus. Bioresour Technol 143:1-9

Breuer G, de Jaeger L, Artus VPG, Martens DE, Springer J, Draaisma RB, Eggink G, Wijffels RH, Lamers PP (2014) Superior triacylglycerol (TAG) accumulation in starchless mutants of Scenedesmus obliquus: (II) evaluation of TAG yield and productivity in controlled photobioreactors. Biotechnol Biofuels 7:70

Chen W, Zhang C, Song L, Sommerfeld M, Hu Q (2009) A high throughput Nile red method for quantitative measurement of neutral lipids in microalgae. J Microbiol Methods 77:41-47

Chisti Y (2007) Biodiesel from microalgae. Biotechnol Adv 25:294-306

de Vree JH, Bosma R, Janssen M, Barbosa MJ, Wijffels RH (2015) Comparison of four outdoor pilot-scale photobioreactors. Biotechnol Biofuels 8:215

Draaisma RB, Wijffels RH, Slegers PM, Brentner LB, Roy A, Barbosa MJ (2013) Food commodities from microalgae. Curr Opin Biotechnol 24:169-177

Fábregas J, Maseda A, Domínguez A, Ferreira M, Otero A (2002) Changes in the cell composition of the marine microalga,
Nannochloropsis gaditana, during a light:dark cycle. Biotechnol Lett 24:1699-1703

Feng P, Deng Z, Hu Z, Fan L (2011) Lipid accumulation and growth of Chlorella zofingiensis in flat plate photobioreactors outdoors. Bioresour Technol 102:10577-10584

Fernandes B, Teixeira J, Dragone G, Vicente AA, Kawano S, Bišová K, Přibyl P, Zachleder V, Vítová M (2013) Relationship between starch and lipid accumulation induced by nutrient depletion and replenishment in the microalga Parachlorella kessleri. Bioresour Technol 144:268-274

Griffiths MJ, Harrison STL (2009) Lipid productivity as a key characteristic for choosing algal species for biodiesel production. J Appl Phycol 21:493-507

Han F, Huang J, Li Y, Wang W, Wan M, Shen G, Wang J (2013) Enhanced lipid productivity of Chlorella pyrenoidosa through the culture strategy of semi-continuous cultivation with nitrogen limitation and $\mathrm{pH}$ control by $\mathrm{CO}_{2}$. Bioresour Technol 136:418-424

Ho SH, Chang JS, Lai YY, Chen CNN (2014) Achieving high lipid productivity of a thermotolerant microalga Desmodesmus sp. F2 by optimizing environmental factors and nutrient conditions. Bioresour Technol 156:108-116

Ho SH, Chen CNN, Lai YY, Lu WB, Chang JS (2014b) Exploring the high lipid production potential of a thermotolerant microalga using statistical optimization and semi-continuous cultivation. Bioresour Technol 163:128-135

Hu Q, Sommerfeld M, Jarvis E, Ghirardi M, Posewitz M, Seibert M, Darzins A (2008) Microalgal triacylglycerols as feedstocks for biofuel production: perspectives and advances. Plant J 54:621-639

Klok AJ, Martens DE, Wijffels RH, Lamers PP (2013) Simultaneous growth and neutral lipid accumulation in microalgae. Bioresour Technol 134:233-243

Klok AJ, Lamers PP, Martens DE, Draaisma RB, Wijffels RH (2014) Edible oils from microalgae: insights in TAG accumulation. Trends Biotechnol 32:521-528

Lucas-Salas LM, Castrillo M, Martínez D (2013) Effects of dilution rate and water reuse on biomass and lipid production of Scenedesmus obliquus in a two-stage novel photobioreactor. Bioresour Technol 143:344-352

Mata TM, Martins AA, Caetano NS (2010) Microalgae for biodiesel production and other applications: a review. Renew Sustain Energy Rev 14:217-232

Mayers JJ, Flynn KJ, Shields RJ (2013) Rapid determination of bulk microalgal biochemical composition by Fourier-Transform Infrared spectroscopy. Bioresour Technol 148:215-220

Miglio R, Palmery S, Salvalaggio M, Carnelli L, Capuano F, Borrelli R (2013) Microalgae triacylglycerols content by FT-IR spectroscopy. J Appl Phycol 25:1621-1631

Molina-Grima E, Belarbi EH, Acién-Fernández FG, Robles Medina A, Chisti Y (2003) Recovery of microalgal biomass and metabolites: process options and economics. Biotechnol Adv 20:491-515

Mulders KJM, Janssen JH, Martens DE, Wijffels RH, Lamers PP (2014) Effect of biomass concentration on secondary carotenoids and triacylglycerol (TAG) accumulation in nitrogen-depleted Chlorella zofingiensis. Algal Res 6:8-16

Mulders KJM, Lamers PP, Wijffels RH, Martens DE (2015) Dynamics of biomass composition and growth during recovery of nitrogenstarved Chromochloris zofingiensis. Appl Microbiol Biotechnol 99:1873-1884

Münkel R, Schmid-Staiger U, Werner A, Hirth T (2013) Optimization of outdoor cultivation in flat panel airlift reactors for lipid production by Chlorella vulgaris. Biotechnol Bioeng 110:2882-2893

Přibyl P, Cepák V, Zachleder V (2013) Production of lipids and formation and mobilization of lipid bodies in Chlorella vulgaris. J Appl Phycol 25:545-553

Quinn JC, Yates T, Douglas N, Weyer K, Butler J, Bradley TH, Lammers PJ (2012) Nannochloropsis production metrics in a scalable outdoor 
photobioreactor for commercial applications. Bioresour Technol 117:164-171

Rodolfi L, Chini Zittelli G, Bassi N, Padovani G, Biondi N, Bonini G, Tredici MR (2009) Microalgae for oil: strain selection, induction of lipid synthesis and outdoor mass cultivation in a low-cost photobioreactor. Biotechnol Bioeng 102:100-112

San Pedro A, González-López CV, Acién-Fernández FG, Molina-Grima E (2014) Outdoor pilot-scale production of Nannochloropsis gaditana: influence of culture parameters and lipid production rates in tubular photobioreactors. Bioresour Technol 169:667-676

Siaut M, Cuiné S, Cagnon C, Fessler B, Nguyen M, Carrier P, Beyly A, Beisson F, Triantaphylidès C, Li-Beisson Y, Peltier $\mathrm{G}$ (2011) Oil accumulation in the model green alga Chlamydomonas reinhardtii: characterization, variability between common laboratory strains and relationship with starch reserves. BMC Biotechnol 11:7

Terigar BG, Theegala CS (2014) Investigating the interdependence between cell density, biomass productivity, and lipid productivity to maximize biofuel feedstock production from outdoor microalgal cultures. Renew Energy 64:238-243
Torzillo G, Sacchi A, Materassi R, Richmond A (1991) Effect of temperature on yield and night biomass loss in Spirulina platensis grown outdoors in tubular photobioreactors. J Appl Phycol 3:103-109

Vanthoor-Koopmans M, Wijffels RH, Barbosa MJ, Eppink MHM (2013) Biorefinery of microalgae for food and fuel. Bioresour Technol 135: $142-149$

Vejrazka C, Janssen M, Streefland M, Wijffels RH (2011) Photosynthetic efficiency of Chlamydomonas reinhardtii in flashing light. Biotechnol Bioeng 108:2905-2913

Wang G, Wang T (2012) Characterization of lipid components in two microalgae for biofuel application. J Am Oil Chem Soc 89:135-143

Wen X, Geng Y, Li Y (2014) Enhanced lipid production in Chlorella pyrenoidosa by continuous culture. Bioresour Technol 161: 297-303

Wijffels RH, Barbosa MJ, Eppink MH (2010) Microalgae for the production of bulk chemicals and biofuels. Biofuels Bioprod Biorefin 4: 287-295

Zemke PE, Wood BD, Dye DJ (2010) Considerations for the maximum production rates of triacylglycerol from microalgae. Biomass Bioenergy 34:145-151 